\title{
Essential aspects in the design of electrochemical biosensors: mini review
}

\begin{abstract}
Electrochemical biosensors are a versatile and promising tool, depending on the selection of its components, which facilitates its use in areas such as clinical diagnosis, food industry, environment monitoring and in other fields, where rapid and reliable analyses are needed.
\end{abstract}

Volume 4 Issue 4 - 2018

\author{
Abel Ibrahim Balbín Tamayo \\ Department of analytical chemistry, University of Havana, Cuba
}

Correspondence: Abel Ibrahim Balbín Tamayo, Assistant Professor of the Department of analytical chemistry, Faculty of chemistry, University of Havana, Cuba, Email Ibrahimaries009@gmail.com

Received: July 23, 2018| Published: August 14, 2018

\section{Introduction}

An electrochemical biosensor is a self-contained integrated device, which is capable of providing specific quantitative or semiquantitative analytical information using a biological recognition element (biochemical receptor) which is retained in direct spatial contact with an electrochemical transduction element. ${ }^{1}$ Figure 1 There are many variants that can be used in the design of a biosensor. From the choice of the type of electrochemical transduction, ${ }^{2,3}$ in correspondence with the analytical signal (), taking into account the molecular recognition element ${ }^{4}$ and the effective immobilization of it on the transducer material. ${ }^{4}$ Thus, how to choose that configuration is what guarantees a useful signal. The selection of the most favorable conformation follows the performance criteria: calibration characteristics (sensitivity, operational and linear concentration range, detection and quantitative determination limits), selectivity, steadystate and transient response times, sample throughput, reproducibility, stability and lifetime. ${ }^{1}$ Electrochemical transduction or detection: The electrochemical biosensors depending on the type of electrochemical transduction can be conduct metric, ${ }^{5}$ potentiometric, ${ }^{6}$ voltammetric / amperometric, ${ }^{7}$ impedance, Ion charge or field effect. ${ }^{8}$

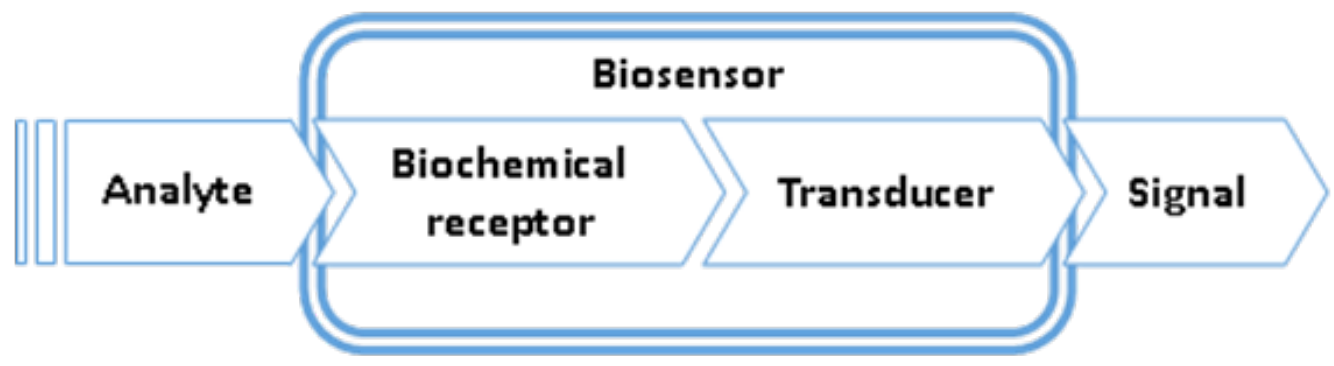

Figure I Basic scheme of a biosensor.

\section{Biological recognition element, receptor}

Biosensors are divided into two large groups according to the recognition mechanism:

Biocatalytic recognition element: the biosensor is based on a reaction catalyzed by macromolecules to notify the molecular recognition event. Enzyme, ${ }^{9}$ whole cells, ${ }^{10}$ Tissue are used. Biocomplexing or bioaffinity recognition element: Based on supramolecular reaction of the key-lock type for the follow-up of the molecular recognition event. Such as, Antibody-antigen interaction, ${ }^{9}$ Receptor/antagonist/agonist and formation of a double stranded DNA on the probe surface. ${ }^{11}$ The application of the catalytic electrochemical biosensors has been the most used in the resolution in real situations, having still much to be developed in the field of electrochemical biosensors affinity.

\section{Immobilization of biological receptors}

The main ways to immobilize the elements of molecular recognition, have been: (a) Entrapment behind a membrane: a solution of enzyme, a suspension of cells or a slice of tissue is, (b) Entrapment of biological receptors within a polymeric matrix, (c) Entrapment of biological receptors within self-assembled monolayers (SAMs) or bilayer lipid membranes (BLMs), (d) Covalent bonding of receptors on membranes or surfaces activated by means of bifunctional, (e) Bulk modification of entire electrode material, e.g. enzyme-modified carbon paste or graphite epoxy resin groups or spacers, such as glutaraldehyde, carbodiimide, SAMs or multilayers, avidin-biotin silanization, ${ }^{5}$ in this sense, the investigations are focused on guaranteeing the capacity of molecular recognition, after being immobilized the receptor phase on the transducer. The best results have been in the immobilization of enzymes by entrapment of biological receptors within a polymeric matrix.

\section{Outlook}

Over the past decade we have witnessed a tremendous progress toward the development of electrochemical biosensors. Such devices are of considerable interest due to their tremendous 
promise for obtaining information in a faster, simpler, and cheaper manner compared to traditional assays. The instrumentation for electrochemical detection is significantly cheaper and smaller than that of comparably sensitive non-electrochemical methods. In addition to excellent economic prospects, such devices offer innovative routes for interfacing (at the molecular level) the recognition and signaltransduction elements.

\section{Acknowledgements}

None.

\section{Conflict of interest}

Author declares that there is no conflict of interest

\section{References}

1. Theâvenot DR, Klara Toth, Richard A Durst, et al. Electrochemical biosensors: recommended definitions and classification. Pure Appl Chem. 1999;71(12):2333-2348.

2. Lima HRS, da Silva JS, de Oliveira Farias EA, et al. Electrochemical sensors and biosensors for the analysis of antineoplastic drugs. Biosens Bioelectron. 2018;108:27-37.

3. Maduraiveeran G, Sasidharan M, Ganesan V. Electrochemical sensor and biosensor platforms based on advanced nanomaterials for biological and biomedical applications. Biosens Bioelectron. 2018;103:113-129.
4. Justino CIL, Ana C Freitas, Ruth Pereira, et al. Recent developments in recognition elements for chemical sensors and biosensors. TrAC Trends in Analytical Chemistry. 2015;68:2-17.

5. Gupta S, Murthy CN, Prabha CR. Recent advances in carbon nanotube based electrochemical biosensors. Int J Biol Macromol. 2018;108:687-703.

6. Mousavi Z, Kim Granholm, Tomasz Sokalski, et al. All-solid-state electrochemical platform for potentiometric measurements. Sensors and Actuators B: Chemical. 2015;207:895-899.

7. Vidal JC, Bonel L, Ezquerra A, et al. Electrochemical affinity biosensors for detection of mycotoxins: A review. Biosens Bioelectron. 2013;49:146158 .

8. Iskierko Z, Noworyta K, Sharma PS. Molecular recognition by synthetic receptors: Application in field-effect transistor based chemosensing. Biosensors and Bioelectronics. 2018;109:50-62.

9. Hasanzadeh MN, Shadjou, M de la Guardia. Nanosized hydrophobic gels: Advanced supramolecules for use in electrochemical bio- and immunosensing. TrAC Trends in Analytical Chemistry. 2018;102:210-224.

10. Burlage RS, Tillmann J. Biosensors of bacterial cells. Journal of Microbiological Methods. 2017;138:2-11.

11. Diculescu, VC, Chiorcea-Paquim AM, Oliveira-Brett AM. Applications of a DNA-electrochemical biosensor. TrAC Trends in Analytical Chemistry. 2016;79:23-36. 